\title{
Raúl Prebisch: historia, pensamiento y vigencia de la teoría de la transformación para el desarrollo de América Latina
}

\section{Raul Prebisch: History, thought and validity of the theory of transformation for Latin America development}

\begin{abstract}
Mario Rapoport
Economista e historiador, doctor en Historia en la Universidad de París I-Sorbona, Director del Instituto de Estudios Históricos, Económicos, Sociales e Internacionales (IDEHESI) del Conicet-UBA mariorapoport@gmail.com

Sebastián Guiñazú

Economista de la Universidad de Buenos Aires. Investigador del Instituto de Estudios Históricos, Económicos, Sociales e Internacionales (IDEHESI) del Conicet-UBA

http://orcid.org/0000-0002-4077-3425 sebastianguinazu@gmail.com
\end{abstract}

Fecha de recepción: 22 de febrero de 2016 Fecha de aceptación: 11 de agosto de 2016

Sugerencia de citación: Rapoport. M. \& Guiñazú, S. (2016). Raúl Prebisch: historia, pensamiento y vigencia de la teoría de la transformación para el desarrollo de América Latina. tiempo\&economía, 3(2), 55-77, doi: http://dx.doi.org/10.21789/24222704.1129

\section{RESUMEN}

Raúl Prebisch fue sin duda uno de los economistas más reconocidos e influyentes de América Latina, tanto por sus aportes teóricos para el desarrollo de la región como por su participación en la creación institucional. En este trabajo nos proponemos repasar en forma paralela 
su vida y pensamiento, destacando los principales debates en los que se vio involucrado. Nos interesa, en particular, resaltar el legado de sus últimas obras, donde completó su teoría sobre el desarrollo latinoamericano a la luz de la vasta experiencia obtenida en su larga trayectoria académica y profesional.

Palabras clave: Raúl Prebisch, historia del pensamiento económico, historia económica de América Latina, desarrollo económico

Códigos JEL: B23, B31 - N16 - O10

\section{Abstract}

Raul Prebisch was undoubtedly one of the most recognized and influential economists in Latin America, both for their theoretical contributions regarding the development of the region and its participation in institutional creation. In this paper we will review in parallel his life and thought, highlighting the main debates in which he has been involved. We are particularly interested in rescuing the legacy of his last works, in which he completed his theory on Latin American development in the light of the vast experience gained during his long academic and professional career.

Keywords: Raul Prebisch, history of economic thought, economic history of Latin America, economic development

JEL Codes: B23, B31 - N16 - O10 


\section{INTRODUCCIÓN}

Este trabajo se propone repasar la vida y el pensamiento de Raúl Prebisch y, en forma más específica, destacar la importancia de la última etapa de su obra. Buscamos aportar una visión integral de este célebre economista analizando, en paralelo y en forma interrelacionada, los principales hechos y acontecimientos de su vida profesional con el desarrollo de su pensamiento. El caso de Prebisch cobra especial singularidad, ya que, además de ser uno de los economistas más reconocidos en la historia de América Latina por su obra intelectual en relación con el desarrollo económico de la región, también tuvo una importante participación institucional. En cuanto a la construcción de su pensamiento, entonces, el autor tuvo el privilegio de confrontar muchas de sus ideas o hipótesis con la realidad, topándose con las dificultades y los desafíos que ello implica.

Nos interesa remarcar el espíritu crítico que acompañó a Raúl Prebisch durante toda su destacada trayectoria, presente ya en sus primeros trabajos como estudiante curioso e inquieto en la Universidad de Buenos Aires, y también en las reflexiones de su última etapa como director de la Revista Cepal. Desde esta perspectiva, prestaremos especial atención a las últimas obras del autor, en las que completó su teoría del desarrollo latinoamericano en forma crítica, sobre la base de la experiencia recogida en su recorrido profesional e intelectual. Asimismo, entendemos que muchas de estas ideas tienen gran vigencia en la actualidad para analizar las dificultades que ha enfrentado América Latina en las últimas décadas, en la búsqueda del desarrollo con inclusión.

En cuanto a su estructura, el trabajo se divide en cuatro partes. En la primera haremos un recorrido por el inicio de su actividad como economista y analizaremos algunas de las obras más controvertidas de su juventud. En la segunda sección repasaremos su madurez profesional, con la fundación del Banco Central de la República Argentina como hecho más destacado. La tercera parte estará dedicada a su actuación institucional en Cepal y Unctad y los debates de aquel entonces en relación con el desarrollo económico de la periferia. En la cuarta parte nos centraremos en sus últimas obras, destacando el modo crítico en el que construye su Teoría de la transformación, y también la vigencia de esta para pensar el desarrollo de Latinoamérica. ${ }^{1}$

1 En cuanto a su pensamiento, Prebisch (1987) considera la existencia de cinco etapas distintas. Sunkel et al. (2013), por su parte, extienden el análisis a seis etapas, al incluir las ideas de su juventud. La diferencia en la periodización que aquí presentamos radica en nuestra intención de utilizar como hilo conductor su actividad profesional, aunque bien podrían reconocerse dichas etapas dentro del relato. 


\section{INICIOS BRILLANTES DE UN ECONOMISTA CRÍTICO}

La actividad académica y pública de Raúl Prebisch, que lo destacó como uno de los fundadores de la Cepal y como alto funcionario de otros organismos internacionales, no comienza, como generalmente se cree, en los años treinta. Se inicia en la Facultad de Ciencias Económicas de la Universidad de Buenos Aires, donde cursó sus estudios entre 1918 y 1921 y publicó una serie de artículos sobre la realidad económica del país.

Prebisch desarrolló desde muy joven sus cualidades como intelectual y economista. Lúcido, pero con espíritu crítico, formado en las enseñanzas de la escuela neoclásica, el joven Prebisch no se sintió cómodo dentro de ese marco teórico. En cambio, fue en búsqueda de elementos que le permitieran la comprensión de la génesis de los fenómenos económicos, transformándose en uno de los más importantes pensadores de la problemática de este lado del mundo: la por él mismo popularizada periferia, evitando acomodar los hechos reales a los dictados de un estrecho economicismo. En palabras de Prebisch: "Proponerse explicar la realidad a la luz de una teoría solamente económica es perderse irremisiblemente en un callejón sin salida" (Prebisch, cit. en Piñeiro Iníguez, 2003, p. 17).

\section{La cuestión social y los ciclos económicos}

Raúl Prebisch comenzó a interesarse en la vida política del país a raíz de las consecuencias de la guerra y la crisis sociopolítica e industrial de la que fue testigo en 1918. Pensó en afiliarse al Partido Socialista, aunque su posterior crítica a las ideas liberales de Juan B. Justo, presidente del partido en aquel entonces, y el disgusto de este lo llevaron a romper su ficha de afiliación antes de oficializar su ingreso (Dosman, 2010).

Su primer artículo lo escribió cuando tenía 19 años, en la revista La Hora. Poco después publicó de nuevo, pero esta vez en la Revista de Ciencias Económicas, un artículo titulado significativamente "La cuestión social". Allí exponía:

Afirmar que la cuestión social no existe en nuestro país significa ignorar la realidad de las cosas, desconociendo la existencia de intereses en pugna entre el proletariado industrial y el capitalismo y entre el proletariado rural y la clase propietaria de las tierras e instrumentos productivos. Negar la cuestión social implica no aceptar la evolución y sí el estancamiento. (Prebisch, [1920] 1991a, p. 340)

Aunque manifestaba, en una nota al pie del mismo texto, que no aceptaba el término lucha de clases en toda la amplitud dada por Marx y Engels y prefería la concepción del socialista Filippo Turati, cuando planteaba, en ciertos casos, la cooperación de clases frente a la lucha.

Con respecto a Juan B. Justo, Prebisch intentó abrir una discusión acerca de sus tesis sobre la moneda y los ciclos. Lo que cuestionaba era la adhesión irreflexiva de aquel a la teoría cuantitativa, y sus afirmaciones acerca de que las causas de las crisis y los ciclos en el país eran exclusivamente producto de la emisión descontrolada de dinero, una idea dominante en los círculos liberales y en algunos sectores del socialismo de aquella época. Justo encontraba la justificación del libre cambio en el menor costo de vida que, según él, esa política representaba para las clases menos favorecidas. 
Si bien Prebisch adhería a los principios de la teoría monetaria existente, señalaba en forma crítica que "cuando las condiciones de hecho en que se afirma esa teoría se modifican, ya sea que otras fuerzas entren en acción o que el Estado exceda los límites que le fijan las leyes económicas, los problemas monetarios adquieren un viso especial, y su estudio, muchas veces, se torna fecundo en conclusiones que amplifican o dan nueva forma a la teoría" (Prebisch, [1920] 1991a, pp. 54-60).

En esta primera etapa, entonces, Raúl Prebisch se dedica al estudio de los ciclos económicos, anticipo de teorías que profundizará luego en la Cepal. Estos trabajos lo llevan a confrontar intelectualmente figuras importantes en la vida académica y política de aquellos años, como el caso citado de Justo, y, sobre todo, el de un distinguido académico conservador, el Dr. Norberto Piñero, quien había escrito un libro sobre problemas relacionados con el sistema bancario y la moneda en el país. ${ }^{2}$ A él, Prebisch dedica su primer gran trabajo: "Anotaciones sobre nuestro medio circulante", en 1921, contando tan solo con 20 años. Una gran influencia para Prebisch la constituyó un libro de John Williams, economista norteamericano que escribió una tesis doctoral en Harvard sobre la economía argentina en las dos últimas décadas del siglo XIX, varios de cuyos capítulos tradujo. ${ }^{3}$

Mediante un análisis pormenorizado de las distintas crisis que había atravesado el país, una de las conclusiones más importantes a la que arriba Prebisch en este artículo es señalar la importancia que tiene el balance de pagos a la hora de explicar las crisis económicas y los ciclos en la economía nacional.

País sin capitales acumulados, y por lo tanto incapaz de mantener moneda propia, la Argentina debía tomarlos en el exterior, ya para desenvolverse económicamente, ya para colmar los déficit en los presupuestos. Los capitales prestados permiten, por una parte, el abultamiento de las importaciones de mercaderías extranjeras, y por otra, al incorporarse como metálico en la economía nacional, aumentan la cantidad de medio circulante, y preparan el terreno para la expansión del crédito y un período ascendente; del mismo modo que es el retraimiento de estos capitales que, junto a la variación de otros factores sobre los que tienen gran influencia, desequilibran el balance de pagos y producen una situación crítica. De tal suerte que estos capitales, como expresamos a su tiempo, constituían los factores objetivos preponderantes en la formación de nuestra crisis. (Prebisch, [1921] 1991a, p. 161)

Según Prebisch, los períodos de auge comenzaban gracias a los saldos positivos en la balanza comercial, aunque luego iban acompañados de una excesiva entrada de capitales externos (endeudamiento). Estas circunstancias eran aprovechadas de forma imprudente por los bancos nacionales, a los que Prebisch destacaba por "la imprevisión, la confianza excesiva y el marcado espíritu de especulación y aventuras financieras" (Prebisch, [1921] 1991a, p. 169), que expandían fuertemente el crédito. Esto provocaba, por un lado, el aumento de las importaciones, y por otro, una presión mayor sobre la balanza de pagos como consecuencia de los servicios de la deuda. En algún momento los capitales se retiraban bruscamente, ya sea porque la economía local se volvía insostenible o por cuestiones externas al país, hecho que conducía a profundas crisis.

2 N. Piñero (1921). La moneda, el crédito y los bancos en la Argentina. Ed. Jesús Menéndez, Buenos Aires.

3 Se trata de John H. Williams, autor del libro Argentine International Trade under Inconvertible Paper Money, 1880-1900, Harvard University Press, 1920.

tiempo\&economía

Vol. $3 \mathrm{~N}^{\circ} 2$ - II semestre de 2016

p. 59 
Llegué a la conclusión de que el Balance de Pagos, las fluctuaciones del Balance de Pagos, tenían una influencia dominante sobre la moneda [...] Pero no se reconocía la influencia del Balance de Pagos como un fenómeno que había que moderar de alguna forma. Porque la tesis dominante, tanto antes como después, era que el dinero y la tasa de interés resolvían espontáneamente el problema. Se exportaba oro, subía la tasa de interés, eso contenía la hemorragia, se atraían fondos a corto plazo y el problema terminaba. Y no era así, porque en este país cuando las cosechas fracasaban o bajaban los precios, era cuando la gente tendía a invertir afuera por temor a las consecuencias. En lugar de atraer el oro, el oro salía. Era contraproducente. (Entrevista de Prebisch por González del Solar en 1983, cit. en Mallorquin, 2006, p. 10)

Estas reflexiones resultarán centrales para la explicación del endeudamiento externo argentino y para el desarrollo de sus ideas sobre las relaciones centro-periferia y la apropiación de los frutos del progreso técnico por parte de los países desarrollados, en gran medida extraídas de esos trabajos sobre la historia económica de su país natal.

\section{El problema de la tierra y el comercio de carnes}

Otros aspectos importantes de la actividad temprana de Raúl Prebisch fueron los trabajos elaborados en relación con la cuestión de la tierra y al comercio de carnes. En un artículo publicado en 1924, denominado "El problema de la tierra", que tenía por base una conferencia que Prebisch había brindado en la ciudad de Melbourne bajo el patrocinio del Henry George Club, analizaba cuestiones relacionadas con la historia de Argentina en el siglo XIX, centrándose principalmente en la cuestión del reparto de las tierras. ${ }^{4}$

En su trabajo, Prebisch ([1924] 1991a, p. 377) señaló:

En la segunda mitad del siglo pasado el gobierno vendió tierra a precios muy baratos, principalmente para obtener recursos y para satisfacer las ambiciones personales de políticos y de sus amigos y parientes. La cría de ganados, en esas condiciones, constituyó la ocupación aristocrática de los argentinos adinerados, quienes llevaban una vida fácil y alegre en la ciudad de Buenos Aires y gastaban frecuentemente en París su dinero, proveniente por lo común del privilegio territorial.

Esta situación seguirá siendo crucial a principios del siglo XX, cuando Prebisch apuntará sus críticas a la ley de arrendamientos y al atraso de los métodos de cultivo, encontrando como responsables a los terratenientes y a la propiedad latifundista, cuya principal consecuencia era impedir la formación de una clase media rural propietaria de tierras. Cualquier tipo de latifundio resultaba perjudicial para el bienestar público porque incrementaba el poder de negociación de los terratenientes frente a los arrendatarios y convertía a los primeros en una especie de señores feudales. A su vez, la remuneración de los peones rurales era muy baja, por lo que el costo laboral constituía una parte menor de los costos totales.

Otra cuestión interesante que Prebisch resaltaba era la distribución de la riqueza y los efectos de la depreciación de la moneda, demostrando que dicha depreciación traía efectos positivos

4 El estadounidense Henry George era un reformador social popularmente conocido por su teoría de que la renta económica de las tierras debía ser participada por la sociedad, en lugar de caer en manos privadas. 
para los ingresos de los terratenientes y, en contraposición, implicaba una disminución de los salarios reales de los trabajadores rurales. Por último, concluye su trabajo sobre esta cuestión con una crítica rotunda a las desigualdades sociales que el sistema generaba, señalando que:

[...] como resultado a la gran desigualdad en la distribución de la riqueza, las más altas clases sociales viven en muy buenas condiciones, mientras la gente obrera y la parte más baja de la clase media llevan en general una existencia muy difícil. Las primeras disfrutan de todos los refinamientos artísticos, literarios, musicales y científicos de la civilización; ellas tienen dinero y ocios para obtenerlos. Los segundos no tienen ni lo uno ni lo otro [...]. Ellos viven en muy incómodas e insalubres condiciones en míseras viviendas de las grandes ciudades, mientras muy cerca de ellos la gente despliega su opulencia en brillantes y costosas residencias o espléndidos palacios. (Prebisch, [1924] 1991a, p. 380)

En relación con estas problemáticas, poco más tarde publicó un trabajo en el que analiza un proyecto de colonización del poder ejecutivo. ${ }^{5}$ Allí señalaba que en Argentina la bibliografía sobre este tema y una posible reforma agraria era muy extensa, a diferencia de países con algunas características similares como Australia o Nueva Zelanda, hecho que atribuía a que en ellos el reparto de la tierra había sido más igualitario:

A cada tentativa de reforma agraria en nuestro país, la agitación de las ideas y el comentario de las leyes extranjeras, enriquecen copiosamente la literatura sobre el problema. Contrasta esta efervescencia de palabras con la acción efectiva, sofocando en un trámite legislativo poco diligente, desvanecida por la influencia de los intereses en que la gran propiedad se apuntala. (Prebisch, [1924] 1991a, p. 393)

En lo que sigue del artículo aparecerá una postura muy radicalizada y poco conocida del joven Prebisch, por la cual asignaba al Estado la potestad de expropiar terrenos para luego venderlos, de forma que pueda lograrse una distribución de la tierra menos concentrada.

En cuanto al comercio de carnes, Prebisch realizó una serie de informes a pedido de la Sociedad Rural Argentina a mediados de la década de 1920, en donde cuestiona la posición oligopólica del capital extranjero. En un trabajo que denominó "El pool de los frigoríficos. Necesidad de la intervención del Estado" (Prebisch, [1927] 1991a, pp. 481-497) señalaba justamente la urgencia de que este último se hiciera cargo de regular la actividad de los frigoríficos, sobre todo estadounidenses y británicos, que manipulaban el mercado a su conveniencia, obteniendo fuertes márgenes en sus ventas al exterior.

Prebisch sostenía que, al combinarse en un pool, los frigoríficos quedaban en una situación de monopolio. Podían así imponer precios bajos a los productores restringiendo las exportaciones al mercado británico para conseguir cotizaciones más altas en desmedro de los consumidores. Este procedimiento sobre los precios, además de dar la posibilidad a esas empresas de obtener "el beneficio máximo, como en las consabidas prácticas monopolistas", ocasionaba pérdidas "que la economía nacional deriva de la producción de ganados". La solución propuesta por Prebisch era regular el pool, tarea que le correspondería al Estado nacional para beneficio de los productores nativos.

5 Raúl Prebisch, “Aclaraciones al proyecto de colonización del poder ejecutivo", en Prebisch (1991a). 


\section{LA MADUREZ PROFESIONAL}

A partir del golpe de Estado de 1930, Raúl Prebisch ocupó distintos cargos de responsabilidad en la administración pública y se transformó en el "cerebro gris" de los equipos económicos de los gobiernos conservadores por más de una década. Le escribía al entonces ministro de Hacienda Federico Pinedo informes y discursos, como el plan de 1940, lo que lo convirtió en el verdadero factotum de las políticas económicas de esa época. También conformó un grupo de técnicos con muchos compañeros de sus años universitarios que hizo entrar a la administración pública. Por lo general, sus recomendaciones y accionar concretos se alejaron de los mandatos ortodoxos, y el Estado comenzó a tener una participación activa en la orientación de la economía.

\section{La creación del "impuesto a los réditos" y el grupo Prebisch}

En 1923, gracias a una beca, Prebisch se dirigió a Australia para estudiar el sistema tributario de aquel país, hecho que sería el germen, años más tarde, en 1932, de la Ley de Impuesto a los Réditos (mucho más progresivo que la tributación existente entonces), un proyecto que él mismo redactó siendo subsecretario de Hacienda en el gobierno de facto del general José F. Uriburu, con quien tenía un cierto parentesco familiar por el lado de su madre, Rosa Linares Uriburu. La creación de este impuesto se debió a los problemas que atravesaban los ingresos fiscales, basados principalmente en los derechos de importación, ante la caída del comercio internacional como resultado de la crisis mundial.

Prebisch mismo se entrevistó con el Presidente, a quien convenció de la necesidad de implementar el proyecto, por el elevado déficit fiscal y la posibilidad de que se desatara un proceso inflacionario. Con su aprobación, elaboró el proyecto en un fin de semana, y Uriburu firmó el decreto el 19 de enero de 1932 (Prebisch, [1932] 1991b, pp. 7-8).

Muchos autores afirman que la política económica en la mayor parte de la década del treinta fue obra del llamado grupo Pinedo-Prebisch. Cierto es que ambos se conocían desde hacía tiempo pero muchas de sus ideas no coincidían, como aquellas que se referían a la necesidad de la creación de un Banco Central, a la que Pinedo en un principio se oponía por sus concepciones liberales y su defensa de la Caja de Conversión (Lorenzutti, 1996). Por otra parte, Prebisch era un técnico, y Pinedo, un político. No obstante, sí es cierto que Prebisch y la mayor parte de sus colaboradores trabajaron como funcionarios en los gobiernos conservadores de Uriburu, Justo y sus continuadores, donde hicieron carrera hasta la llegada de Perón (Mallorquin, 2006). Fue una intelligentsia proveniente en gran medida de sectores con un pasado socialista o reformista la que manejó la política económica de la república conservadora en los años treinta. Cuando Pinedo devino ministro, en agosto de 1933, Prebisch ya no era más subsecretario de Hacienda, pero fue su principal asesor y, de hecho, elaboró políticas fundamentales del gobierno de Justo. ${ }^{6}$

Lo más destacado de este período fue la creciente participación del Estado en la economía. Por supuesto, en esto estaban interesadas las élites tradicionales, otrora partidarias de la mayor libertad de los mercados, que ahora necesitaban de la actividad estatal para defender sus

6 Para saber más sobre este tema ver Rapoport (2014). 
intereses amenazados por la crisis, como por ejemplo, la creación de Juntas Reguladoras de Granos y de Carnes, cuyo objetivo era proteger a los sectores agropecuarios de los avatares de los precios en los deprimidos mercados mundiales.

De todos modos, muchas de estas ideas se acoplaban con los intereses británicos, que, para hacer frente a la crisis mundial, también habían abandonado el libre comercio y vuelto al sistema proteccionista de las preferencias imperiales expresadas en el Tratado de Ottawa de 1932. Prebisch participó activamente en la firma del Pacto Roca-Runciman (1933), acuerdo que otorgaba amplias concesiones a Gran Bretaña y a la oligarquía ganadera. Este Pacto desató numerosas polémicas en aquel momento y fue objeto de intensos debates historiográficos. Para la mayoría de los estudiosos del tema, constituyó un ataque a los intereses nacionales, porque, a cambio de mantener una cuota en el comercio de carnes con los ingleses, otorgó a estos grandes concesiones en el manejo del tipo de cambio y de los aranceles, ofreció un tratamiento benevolente a sus inversiones y les adjudicó otros privilegios, que internamente solo beneficiaron a un sector reducido de la élite ganadera. Prebisch justificó posteriormente su actuación en el poco defendible Pacto diciendo que no había otra alternativa posible, lo que ha sido refutado por diversos autores. ${ }^{7}$

\section{La creación y dirección del Banco Central}

La idea de la creación de un Banco Central venía madurando desde hacía varios años. Ya en 1917, el presidente radical Hipólito Yrigoyen había propuesto la creación de un Banco de la República sobre la base de capitales estatales y la garantía por parte de la Nación de sus operaciones. Sin embargo, este y otros intentos fueron frenados por el Congreso, donde la oposición conservadora contaba con la mayoría. El escenario cambió con la crisis de 1929, cuando se evidenció que el sistema de la Caja de Conversión era ineficiente para evitar la fuga de oro o la devaluación durante las crisis. Su innegable rigidez en épocas de convertibilidad impedía el manejo de la política monetaria, mientras que en momentos de inconvertibilidad fomentaba el emisionismo incontrolado.

Especialistas norteamericanos y británicos ya estaban asesorando desde comienzos de la década de 1930 a los países del continente en materia financiera. Como el proyecto que un experto inglés, Sir Otto Niemeyer, había realizado para Brasil, o los elaborados por el estadounidense Kemmerer para varios países andinos. No es casual, entonces, que se invitara al mismo Niemeyer a Argentina en 1932, para realizar una evaluación del sistema financiero y aconsejar una serie de medidas necesarias para su mejor funcionamiento, quien elaboró en 1933 un informe donde diseñaba los mecanismos del futuro Banco Central. El Gobierno, a instancias del ministro Pinedo, aprobó en mayo de 1935 un proyecto que, en su concepción de la política bancaria, difería de las propuestas de Niemeyer y fue discutido ardorosamente en el Congreso.

El principal ideólogo del proyecto finalmente aprobado fue el mismo Prebisch, que, como señalan Caldentey y Vernengo (2012), estaba cada vez más influenciado por las ideas anticíclicas de John Maynard Keynes. La nueva institución debía transformarse así en un instrumento lo suficientemente flexible como para aplicar políticas monetarias expansivas

7 Los debates en relación con el Pacto Roca-Runciman pueden verse en Rapoport (2012, pp. 210-214). 
durante los momentos de depresión y contractivas durante los de expansión, esto es, una política que atemperara la amplitud de las fluctuaciones coyunturales.

La propuesta de Niemeyer, en opinión del mismo Prebisch, era demasiado ortodoxa y limitaba severamente la autoridad discrecional del banco al imponer un patrón oro modificado. Por ejemplo, en el proyecto del inglés se proponía la elevación de la tasa de redescuento del Banco Central cuando la proporción de la reserva monetaria con respecto a los billetes fuera inferior al 33\%. El proyecto de Prebisch no contenía esta medida restrictiva, al considerar que hubiera repercutido negativamente en la situación económica. En su propuesta también incorporaba al Banco Central el manejo del control de cambios para mitigar mejor los efectos sobre la economía de las fluctuaciones externas indeseables. El de Niemeyer, en cambio, carecía de tal instrumento (González y Pollok, 1991).

En principio, el Banco Central sería una entidad completamente privada, aunque esa idea no prosperó. El Estado terminó aportando el 50\% del capital accionario, y el Presidente del BCRA sería designado por el poder ejecutivo a partir de una terna presentada por la Asamblea de Accionistas, en la que el Estado no tenía participación: la excepción fue la primera autoridad de la institución, Enrique Bosch, directamente nombrado por el general Justo. Raúl Prebisch, por su parte, se hizo cargo de la gerencia general del Banco (Lorenzutti, 1996).

\section{EL DESARROLLO DESDE UNA PERSPECTIVA PERIFÉRICA}

Considerado un hombre del régimen conservador, en 1943 -luego del golpe de Estado de junio de ese año que abriría el paso al peronismo-, Prebisch fue destituido del BCRA y del cargo de asesor del Gobierno. Alejado de la administración pública, en esta etapa se dedicó por completo a la enseñanza y a la consultoría internacional, donde se destaca su rol como asesor en la reforma de los bancos centrales de distintos países de América Latina (Sunkel et al. 2013).

Un elemento importante de este período es su interpretación crítica de las ideas de John Maynard Keynes, autor que ejerció una gran influencia en Prebisch. La aproximación intelectual al economista inglés podría describirse en cuatro etapas (Mallorquin, 2015). En primer lugar, comenzó cuestionando la perspectiva clásica sobre el comercio internacional subrayando la inoperancia de las reglas impuestas por el patrón oro, así como sus efectos asimétricos para la periferia. Luego se produjo la incorporación de cierto vocabulario de Keynes a la noción del ciclo propuesta por Prebisch. Estos estudios lo llevaron, en 1947, a la publicación de un libro introductorio del economista de Cambridge. ${ }^{8}$ Por último, la consolidación de su crítica a Keynes se produjo dos años más tarde, en una serie de conferencias brindadas en México, donde expone su Teoría dinámica de la Economía (Mallorquin, 2015; Caldentey y Vernengo, 2013).

\section{Cepal: hacia la construcción de una nueva teoría del desarrollo económico}

En 1949 Prebisch abandonó finalmente su actividad docente y su país para dirigirse a Santiago de Chile e iniciar en la Cepal una nueva etapa de su vida académica y pública. Es desde

8 Se trata de Prebisch (1947). Introducción a Keynes. Fondo de Cultura Económica, México. 
allí donde comienza a ejercer una influencia decisiva en torno a la problemática del desarrollo económico de América Latina. Se trata del problema de las relaciones económicas entre el centro y la periferia, caracterizado por la caída de los términos de intercambio, la apropiación de los frutos del progreso técnico por parte de los países centrales y el efecto negativo de los ciclos de los centros. Esta etapa en la vida y el pensamiento de Raúl Prebisch es, quizás, la más explorada, por su importancia pionera en la elaboración de teorías del desarrollo económico de la periferia.

Ante la evidencia de que el progreso económico no se había distribuido en forma equitativa en todos los países, emergieron en esta época teorías que buscaban explicar el atraso relativo de algunos en relación con otros y discutían también las mejores formas de superar esta situación. Surgieron así ideas como las que luego se materializarán en los trabajos de Ragnar Nurkse (1953) y William Arthur Lewis (1954), quienes coincidían en marcar las deficiencias internas de los países subdesarrollados para lograr niveles óptimos de ahorro interno como principal traba para su progreso. Otra figura destacada de la época fue Walter W. Rostow. Este autor señalaba la existencia de distintas etapas obligadas que debían atravesar los países para alcanzar el desarrollo. Según Rostow ([1960] 1990), las primeras fases se caracterizan por fuertes desigualdades económicas, pero luego el libre desenvolvimiento de las leyes del mercado y la especialización en el comercio internacional en los sectores con ventajas comparativas permitirían superar esta situación.

Una explicación alternativa de estos asuntos comenzó a gestarse en la Cepal, cuyo texto fundacional fue escrito por Raúl Prebisch, en 1949. Si bien este órgano fue creado por las Naciones Unidas, contaba con la autonomía suficiente para criticar cuestiones profundas en relación con el comercio internacional y sus implicancias en las posibilidades de desarrollo de los países periféricos.

Prebisch (1949) consideraba que era, en realidad, la inserción desigual en el comercio internacional lo que ocasionaba las diferencias fundamentales entre las naciones, configurándose un sistema de relaciones centro-periferia que atentaba contra el desarrollo de los países de la periferia, en vez de fomentarlo. Según el autor, mientras que los países industrializados lograban absorber los beneficios de los progresos tecnológicos, los países exportadores de materias primas se veían perjudicados por el deterioro en los términos de intercambio de sus productos. La explicación de esta dinámica radicaba en la menor elasticidad-ingreso de los bienes primarios y en la mayor capacidad de negociación de la fuerza laboral en los países industriales, que imponía rigideces a la baja de los precios de sus productos.

De esta forma, Prebisch cuestionaba directamente uno de los pilares básicos de la economía liberal: el que afirma que cada país debe especializarse según sus ventajas comparativas. Esto no era, para él, más que un eufemismo que condena a los países en desarrollo a perpetuarse en condiciones de pobreza y atraso. Retoma, así, lo que ya planteaba con mayor crudeza en sus clases en la Universidad de Buenos Aires, en 1948:

Nos parecería menos justificable [...] que A pretenda demostrar a B [se refiere a países periféricos como Argentina] que la política proteccionista de B conspira contra los sagrados principios de la economía clásica [...] yo voy a decir a ustedes que ese país A tiene mucho de las características de otro gran país industrial cuyas política económica e ideología durante las dos guerras es muy similar al expuesto, y que no es otro que los Estados Unidos. (Prebisch, 1948, p. 43) 
Para superar la situación de atraso, Prebisch consideraba fundamental que los países periféricos se enfocaran en el desarrollo del sector industrial, para lo cual el Estado debía cumplir un rol activo. Esto lo llevó a tomar una postura favorable frente a los procesos de industrialización que estaban teniendo lugar en América Latina, a través de la sustitución de importaciones:

La industrialización de América Latina no es un error económico ni la consecuencia de designios nacionalistas, por más que a veces vaya acompañada de ciertas manifestaciones de exaltación nacional y en otras se haya cometido deplorables errores. La industrialización es una imposición ineludible del desarrollo económico. (Prebisch, cit. en Cepal, 1954, p. 53)

En el esquema originario de la Cepal, la industrialización debía lograrse a través de instrumentos de planeación del Estado, compatibles con la actividad privada y acompañados de un aumento de las exportaciones de las actividades primarias. Estas representarían la fuente principal de divisas y podrían complementarse con inversiones extranjeras orientadas a la industria. La sustitución de importaciones se imponía como una necesidad frente a la inestabilidad del comercio internacional y las desventajas que este presentaba a los países periféricos.

\section{La participación de Prebisch en la Unctad y la cooperación centro-periferia}

En 1955, Prebisch vuelve a Argentina convocado por el gobierno militar que derrocó a Perón y elabora un plan económico, conocido entonces como el Plan Prebisch. Arturo Jauretche, intelectual argentino, enjuicia ácidamente este hecho, incluso más que su participación en el Pacto Roca-Runciman. ${ }^{9}$ En dicho Plan se brinda un diagnóstico muy negativo de la situación económica de entonces, influenciado por hechos de su pasado y el entorno liberal y antiperonista, y propone un programa de acción diferente, en muchos de sus principales contenidos, a las propuestas de la Cepal, que entonces dirige.

Ya hacia principios de la década de 1960, Prebisch es designado secretario general de la Conferencia de las Naciones Unidas sobre Comercio y Desarrollo (Unctad), y se convierte así definitivamente en el emisario de los países del tercer mundo en la ONU. Esto le permitirá ganar un gran reconocimiento internacional y obtener mayores espacios para reforzar su prédica sobre las teorías centro-periferia.

Durante este período profundizará algunos de los conceptos del desarrollo periférico, elaborados durante su época en Cepal. Un elemento distintivo de esta etapa será la importancia asignada a los intentos de avanzar en la cooperación Norte-Sur.

El nuevo giro que está tomando el concepto mismo de la cooperación internacional es de importancia decisiva para esta política de desarrollo. Cuando la aportación de recursos internacionales solo perseguía la explotación de los recursos periféricos para favorecer el desarrollo de los centros, la penetración unilateral de la técnica de los países de producción primaria era del todo compatible con la preservación de estas estructuras tradicionales [...] La cooperación internacional tiende ahora hacia un designio muy diferente: ayudar a los países en desarrollo a acelerar su propia tasa de crecimiento y corregir las grandes disparidades en la distribución del ingreso para mejorar el nivel de vida de las masas populares. (Prebisch, 1973, p. 6)

9 Ver Altamirano (2001). 
La participación de Prebisch en la Unctad y sus esfuerzos por lograr la cooperación entre el centro y la periferia coincidieron en América Latina con el surgimiento de gobiernos desarrollistas, como fueron los casos de Arturo Frondizi en Argentina (1958-1962) y Juscelino Kubitschek en Brasil (1956-1961). Estos se inspiraban en las ideas de la Cepal en relación con la necesidad de avanzar en los procesos de industrialización, a la vez que veían en el escenario internacional ciertas posibilidades de obtener la colaboración de los países centrales, más precisamente de Estados Unidos, que por temor a la propagación del comunismo en América Latina se mostraba dispuesto a cooperar con el desarrollo de los países de la región.

De hecho, las ideas de Prebisch sobre la necesidad de cooperación influyeron también al presidente norteamericano J. F. Kennedy, que en 1961 lanzó el proyecto Alianza para el Progreso, en cuyos documentos fundacionales se hace alusión a la necesidad de llevar adelante transformaciones estructurales en América Latina a nivel económico y social. La Alianza contemplaba transferencias de fondos y ayuda directa en la implementación de programas sociales. El mismo Prebisch formó parte de la elaboración de los documentos de lanzamiento y hasta tuvo una entrevista con Kennedy (Dosman, 2010). Así relataba el economista argentino su participación en este programa:

En cuanto a la Alianza para el Progreso, debo decirle que yo no fui su promotor, pero me subí al carro tan pronto como comenzó a moverse [...] Los documentos de la Cepal fueron la base, y nuestra presencia otro aporte. (Cit. en Pollock et al., 2013, p. 18)

Lo cierto es que finalmente la cooperación prometida por la Alianza para el Progreso no llegó a concretarse. A partir del inicio de la guerra de Vietnam y el asesinato de Kennedy, la postura a favor de la cooperación en Estados Unidos se debilitó considerablemente, dejando lugar a sus clásicas intervenciones militares y a las recomendaciones liberales de los organismos financieros internacionales.

\section{Los debates en torno al desarrollo en América Latina}

El proyecto cepalino había despertado muchas esperanzas, pero ya en la década de 1960 comenzó a recibir duros cuestionamientos por parte de grupos de intelectuales de izquierda y organizaciones políticas de dicha orientación ideológica. En América Latina continuaban la marginación y la pobreza de vastos sectores; la entrada del capital extranjero había generado una mayor dependencia de las importaciones de máquinas y equipos, así como también un continuo drenaje de divisas por la remesa de utilidades y pago de regalías. Estos factores ocasionaban recurrentes crisis de balanzas de pagos que afectaban sobre todo a los estratos más bajos.

A la corriente crítica de las ideas de la Cepal se la conoció como la teoría de la dependencia. Según esta corriente, que proponía una visión histórica y holística de la periferia, el atraso de ciertos países era consecuencia del sistema capitalista mundial. Para ellos el desarrollo de los países adelantados y el subdesarrollo de la periferia no eran fenómenos independientes, sino partes de un mismo proceso, cuya característica fundamental era el traspaso del excedente económico de la periferia al centro mediante distintos mecanismos. El brasileño Ruy Marini (1994, p. 256), uno de sus principales exponentes, señalaba: 
Así es como, fiel a la idea del desarrollo económico como un continuum, ella [la teoría cepalina] no consideraba el desarrollo y el subdesarrollo como fenómenos cualitativamente distintos, signados por el antagonismo y la complementariedad sino tan solo como expresiones cuantitativamente diferenciadas del proceso histórico de acumulación de capital.

Más allá de estos y otros puntos en común que compartían los teóricos de la dependencia, existieron también diferencias muy profundas entre ellos, cuyo análisis escapa al alcance de este trabajo. Lo que nos interesa remarcar es su postura decididamente contraria a la posibilidad de que exista cooperación entre los países desarrollados y los subdesarrollados. En mayor o menor medida, los dependentistas se adherían a la teoría del imperialismo.

Si bien Prebisch nunca adoptó estas ideas, tras numerosos intentos fallidos por lograr la cooperación Norte-Sur, terminaría por volverse escéptico sobre la posibilidad de que los países centrales colaboren decididamente con el desarrollo de la periferia. En relación con su participación en la Unctad, él mismo manifiesta:

No tuve éxito, lo que constituye una prueba clara de que el Norte no estaba dispuesto a actuar, ni el Sur estaba inclinado a realizar las grandes transformaciones estructurales que se requerían para allanar el camino del desarrollo económico y la equidad social. (Prebisch, 1983, p. 349)

Esta experiencia frustrada le permitirá desarrollar una nueva visión acerca de las relaciones entre los países céntricos y los periféricos, en la cual reconocerá el uso de mecanismos hegemónicos por parte de los primeros para hacer prevalecer sus intereses por sobre el resto.

Esta hegemonía se manifiesta en distintas formas y grados sobre los países periféricos, en el empeño de los centros por promover y defender sus intereses económicos, políticos y estratégicos. Y en el ejercicio directo de esa hegemonía los centros tienen instrumentos poderosos: la cooperación financiera, económica y tecnológica, así como la ayuda militar. (Prebisch, 1980a, p. 61)

Ahora bien, más allá de estos cambios en su postura acerca de la posibilidad de cooperación, Prebisch seguirá siendo crítico de los autores y las corrientes políticas que ven en la dependencia toda la explicación del problema del subdesarrollo: "nada se gana en el campo de la teoría, como así tampoco en el de la praxis, con este género de afirmaciones, lo cual no significa negarles eficacia en el adoctrinamiento político" (Prebisch, 1980a, p. 63).

\section{LA TEORÍA DE LA TRANSFORMACIÓN}

En 1976, Raúl Prebisch vuelve a la Cepal, esta vez como director de la revista de dicha institución. Allí publicó una serie de artículos en los que pueden apreciarse agudas reflexiones acerca del desarrollo latinoamericano, elaboradas a la luz de su destacada experiencia profesional.

Esta etapa es, quizás, la más interesante de su pensamiento. Alejado de la vida institucional y las responsabilidades de la gestión, Prebisch se aboca por completo a la culminación de sus ideas. En línea con el espíritu que ya había mostrado en sus épocas de juventud, el autor repasará en forma crítica, incluso, muchas de sus propias posturas anteriores. 
Me formulé otra vez algunos interrogantes de importancia fundamental que había dejado antes sin respuestas convincentes. ¿Por qué se ve acompañado el proceso de desarrollo por el aumento de las disparidades del ingreso y la riqueza? ¿Por qué es tan persistente la inflación y por qué no responde a los remedios tradicionales? ¿Cuáles razones explican algunas contradicciones importantes del proceso de desarrollo de la periferia que no han ocurrido en el desarrollo histórico de los centros, por lo menos con una intensidad comparable? ¿Por qué se ha quedado atrás la periferia? (Prebisch, 1983, p. 1087)

Estas preguntas son las que guiarán las últimas obras de Prebisch. Sus esfuerzos en esta etapa estarán orientados a la construcción de una teoría que sirva de base para llevar adelante las transformaciones necesarias que requiere la periferia. En este período, su pensamiento irá más allá de lo estrictamente económico. La experiencia de Prebisch lo llevará a afirmar lo que ya mencionaba intuitivamente en su juventud: no se puede concebir la economía escindida de las cuestiones sociales y políticas, y viceversa.

\section{Subdesarrollo, distribución desigual del ingreso y excedente}

Si bien escapa al alcance de este trabajo presentar en forma detallada lo que Prebisch (1980a, 1981) denomina la Teoría de la transformación, sí nos interesa repasar sus principales ideas, sobre todo aquellas que, entendemos, son de gran utilidad para analizar las dificultades que ha atravesado la región en la búsqueda de un desarrollo con inclusión.

La cuestión central que apunta Prebisch es que los países periféricos, por cuestiones históricas que pueden variar de unos a otros, poseen características estructurales que impiden que las políticas ortodoxas o liberales que se pregonan desde los centros hegemónicos conduzcan a un desarrollo estable y progresivo. El meollo del asunto está en la forma en que se utiliza en la periferia el excedente económico generado por la actividad productiva. ${ }^{10}$

Según el autor, la estructura social y las grandes desigualdades que presentan los países subdesarrollados tienen implicancias negativas en el uso dinámico del excedente (Prebisch, 1980a, 1981). Esto se explica por el hecho de que los sectores privilegiados, que acaparan gran parte del ingreso, son los que configuran, a través de formas de consumo imitativas de los países centrales, el modo en que el capital se acumula.

La privilegiada sociedad de consumo resulta nociva para la acumulación de capital reproductivo, ya que promueve una diversificación prematura de la demanda con efectos sociales adversos, a lo que debe añadirse la absorción desproporcionada del ingreso por parte de los centros, sobre todo a través de las empresas transnacionales, íntimamente ligadas a la sociedad privilegiada de consumo. (Prebisch, 1983, p. 350)

10 El concepto excedente económico surge ya desde los orígenes de la economía política clásica, y puede encontrarse sobre todo en autores como Ricardo y Marx (Garegnani, 1984). Para profundizar sobre la dinámica entre la apropiación del excedente y la acumulación pueden verse también Furtado (1978) y Di Filippo (1984). 
La demanda de estos sectores imprime al capital un uso consuntivo, ${ }^{11}$ en vez de reproductivo, siendo este último el que permite obtener aumentos en la productividad y un proceso multiplicador del empleo.

La desigual distribución influye de dos maneras principales sobre la estructura productiva. Por un lado, imprime a la demanda una conformación que hace desperdiciar capital físico y fuerza de trabajo; y, por otro, promueve cierta elección de técnicas, y por tanto formas de acumulación, que también representan un desperdicio de recursos productivos. (Prebisch, 1980a, p. 27)

Esta modalidad en la utilización del excedente impide alcanzar el nivel de acumulación necesario para incluir a la totalidad de la fuerza de trabajo a través de aumentos genuinos en la productividad. La dinámica de la economía está marcada por ciclos inestables y crisis inflacionarias. En caso de que se produzca un período prolongado de crecimiento, esto aumentará también el poder de la clase trabajadora y, por consiguiente, su capacidad de negociación salarial. En la medida en que el excedente se incremente se podrán satisfacer estas demandas sin comprometer los intereses de las clases privilegiadas. Sin embargo, la forma no reproductiva en que es utilizado el capital impedirá que la acumulación logre acompañar este proceso. En algún momento se alcanzará un punto crítico, signado por la escasez de divisas, pujas distributivas y tensiones inflacionarias que conllevarán, tarde o temprano, la crisis del sistema (Prebisch, 1981).

Los ciclos económicos son acompañados de modificaciones en la estructura social, que generan impacto también en el escenario político. En la etapa ascendente prevalece un incremento de los estratos intermedios, conformados por la fuerza de trabajo de mayor calificación. Estos amplían su poder político y sindical ejerciendo una presión creciente sobre el excedente. A medida que este compartimiento se consigue, tiende a extenderse socialmente hacia abajo la imitación de las formas de consumo de los centros. Esta etapa suele estar acompañada también del Estado, en un rol activo a favor de la redistribución, aunque sin comprometer las cuestiones estructurales. La crisis del sistema puede postergarse por un tiempo, incluso largo, cuando se dispone de recursos provenientes de la explotación de la riqueza natural no renovable (Prebisch, 1981).

No obstante, los estratos superiores, que poseen la clave dinámica del sistema por concentrar la mayor parte de los medios productivos, no aceptan que disminuya su participación relativa sobre el excedente. Una nueva fase conflictiva del ciclo comienza cuando esta doble presión sobre el excedente supera la capacidad del sistema de satisfacer la demanda de los distintos estratos. Las empresas reaccionan elevando los precios para restablecer la dinámica del excedente, a lo cual sigue la contrarreacción de la fuerza de trabajo, con el alza consiguiente de los salarios nominales, en la medida que tenga suficiente poder para hacerlo. Se origina así la espiral inflacionaria. En esta fase conflictiva, el poder político de los estratos superiores, que parecía ir declinando a medida que avanzaba el proceso redistributivo, irrumpe nuevamente cuando los trastornos provocados por la crisis inflacionaria traen consigo el desquicio económico y la desintegración social (Prebisch, 1981).

11 Algunos ejemplos de acumulación consuntiva pueden ser el desarrollo excesivo de servicios de consumo para las clases medias y altas o la construcción de viviendas con fines especulativos. 
El desenlace de este proceso conduce a una nueva etapa del ciclo, caracterizada por el ajuste y depresión de la economía. A través del disciplinamiento de la fuerza de trabajo, producto del desempleo creciente y el uso represivo del aparato estatal, se revierte el proceso de distribución del ingreso y el excedente vuelve a fluir a los estratos superiores. Algunas de las medidas más comunes para combatir la inflación suelen ser la suba de la tasa de interés y el aperturismo comercial, que, más allá de su efectividad para restablecer la estabilidad macroeconómica en el corto plazo, Prebisch $(1980 a, 1981)$ considera nocivas para la economía por favorecer la concentración del ingreso, las actividades especulativas y la acumulación consuntiva. En la medida que el descontento social se incrementa van generándose las condiciones políticas para una nueva fase del ciclo, con acento en la redistribución, aunque con las dificultades estructurales ya señaladas.

Desde esta perspectiva cíclica, la crítica de Prebisch no se centra únicamente en las expresiones políticas ligadas al liberalismo económico sino también en aquellos movimientos que pregonan la distribución sin apuntar a las cuestiones estructurales. El autor considera que es, en parte, la falta de una teoría apropiada para la interpretación de las consecuencias dinámicas de la apropiación del excedente económico lo que ocasiona los movimientos pendulares tan abruptos que caracterizan a América Latina.

Hay, pues, dos males que atacar, dos males estrechamente ligados entre sí que no admiten arbitraria segregación. Sin embargo, unos ponen toda su atención en la pobreza y otros en la espiral; todo depende del cristal con que se mira. Y unos y otros se abstienen generalmente de penetrar en las raíces profundas de esos males. (Prebisch, 1980a, p. 55)

En cuanto a las relaciones centro-periferia y la división internacional del trabajo, Prebisch retoma sus ideas pioneras de la Cepal: remarca el carácter centrípeto del capitalismo avanzado y plantea como uno de los principales problemas la retención por parte de los centros de los frutos de su progreso técnico. A su vez, vislumbra ya las profundas transformaciones que se producirían en el comercio internacional en lo que respecta a la diversificación de la producción y la demanda y la centralidad de la innovación tecnológica. Estas cuestiones lo llevarán a reforzar sus críticas hacia la teoría de las ventajas comparativas postuladas por los economistas liberales e insistir en la necesidad de la región de emprender un proceso de industrialización que permita acompañar las etapas de crecimiento económico con aumentos en la productividad y una mayor calificación de la fuerza de trabajo.

Algunos de estos temas fueron trabajados también por otros destacados autores de la Cepal. Osvaldo Sunkel, por ejemplo, en un importante artículo publicado en 1971 denominado "Capitalismo transnacional y desintegración nacional", analizaba ya la vinculación entre los intereses y las formas culturales de las minorías privilegiadas en los países periféricos y las sociedades industrializadas. Este autor compartió también trabajos pioneros con Prebisch acerca del impacto sobre el medioambiente de las formas modernas de consumo (Prebisch, 1980b).

\section{Esbozos de la transformación}

En el caso de Prebisch, su caracterización del capitalismo periférico lo llevará a tomar una postura radical en su interpretación de las transformaciones necesarias que deberían llevarse a cabo para superar la situación de atraso: 
Tras larga observación de los hechos y mucha reflexión, me he convencido de que las grandes fallas del desarrollo latinoamericano carecen de solución dentro del sistema prevaleciente. Hay que transformarlo [...] es un sistema socialmente vicioso [...] Muy serias son las contradicciones que allí se presentan: prosperidad, y a veces opulencia, en un extremo; persistente pobreza por el otro. Es un sistema excluyente. (Prebisch, 1981, pp. 102-103)

Algunas de sus recomendaciones aparecen en lo que él denomina Teoría de la transformación (Prebisch, 1980a, 1981). En sus propias palabras, la transformación del sistema debería incluir una "síntesis entre socialismo y liberalismo o, si se quiere, una versión del socialismo basada en la libertad del individuo y en nuevas formas de convivencia social" (Prebisch, 1980a, p. 32). En cuanto al socialismo, se refiere a que el excedente no deberá emplearse según decisiones individuales sino colectivas, a través de la gravitación del Estado, destinadas a elevar el ritmo de acumulación de capital y corregir las diferencias estructurales en la distribución del ingreso. En lo que respecta al liberalismo, el autor plantea que el ingreso así distribuido podrá usarse en el mercado conforme a las decisiones individuales, y que las empresas son las que deberán decidir cómo responder mejor a la demanda, asignando según su juicio el capital que les correspondiese.

Según Prebisch (1980a, 1981), la clave dinámica de la transformación radica en imprimir al excedente un uso reproductivo, que permita acompañar las etapas de crecimiento económico con aumentos en la productividad y la generación de empleo calificado. De esta forma podría alcanzarse un proceso virtuoso, en donde los incrementos de capital reproductivo se traduzcan en efectos multiplicadores sobre el empleo, y la mayor calificación de este permita lograr una redistribución dinámica del ingreso.

El objetivo primordial del plan es elevar el ritmo de acumulación de capital en bienes físicos y formación humana, a fin de aumentar intensamente el empleo con creciente productividad y lograr en esta forma una redistribución dinámica del ingreso. (Prebisch, 1981, p. 292)

Según el autor, en la periferia se presenta el desafío de resolver, a la vez y en forma dinámica, los problemas de acumulación (oferta) y distribución (demanda). En este sentido, Prebisch propone dos mecanismos principales como motores de la transformación.

En primer lugar, por el lado de la oferta, ante la evidencia de que el excedente apropiado por los estratos superiores imprime al capital un uso consuntivo y no reproductivo, el autor asigna al Estado un rol importante para la corrección de este mal. Prebisch considera que este debería encargarse de canalizar el excedente económico con base en consensos democráticos, a través de la combinación de decisiones políticas y técnicas.

Estas medidas deben ser compatibles con la acumulación por parte de las empresas pero pueden modificar el sistema de incentivos. Para ello, destaca la necesidad de un conjunto de modificaciones fiscales y financieras que permitan al Estado cumplir funciones de "promoción de gran significado dinámico, para lo cual requiere un mecanismo que canalice recursos financieros y técnicos y promueva la investigación tecnológica" (Prebisch, 1981, p. 313). En este sentido, el autor destaca la importancia de apoyar a las empresas más dinámicas en la generación de excedente, y también a las pequeñas y medianas, con el objetivo de aumentar la productividad de estas. 
La mayor acumulación de capital deberá realizarse en su mayor parte en las mismas empresas en donde se genera el excedente. Éste sería uno de los estímulos al crecimiento de ellas [...] Otra parte tendría que destinarse a las tareas de promoción del Estado, ya se trate de las empresas existentes o del apoyo de la formación de nuevas empresas y a la evolución de las empresas pequeñas y medianas. (Prebisch, 1981, p. 294)

En materia de comercio exterior, Prebisch justifica el uso de impuestos y subsidios, con el fin de influir sobre la estructura productiva, y pondera la importancia de la integración regional como potenciador del proceso de industrialización. Por otro lado, para algunos sectores claves de la economía, el autor considera necesaria la gestión directa del Estado a través de empresas de propiedad pública:

En cuanto a las empresas de propiedad del Estado, son bien conocidos los motivos que las justifican. Se refieren, sobre todo, a aquellos casos de actividades que por su índole se sustraen a la concurrencia del mercado, a casos donde por sus dimensiones y complejidad técnica es importante la promoción y gestión inicial por el Estado, y al designio de contrarrestar la penetración de la empresa extranjera en campos privativos de decisión del propio país. (Prebisch, 1981, p. 297)

Ahora bien, Prebisch señala algunas cuestiones clave que atañen a la interacción entre estas trasformaciones en la acumulación y aquellas vinculadas a la redistribución dinámica del ingreso. En primer lugar, considera que una condición necesaria para el desarrollo es la estabilidad macroeconómica. En materia fiscal, el rol activo del Estado debe estar acompañado, entonces, de una mayor capacidad de este para captar recursos de la economía.

Para ello, los impuestos progresivos sobre los ingresos cumplirán un doble papel, permitiendo, por un lado, financiar las políticas de promoción del Estado y, por otro, reducir la parte del excedente que es acaparada por los estratos superiores. Una fuente importante de ingresos fiscales que menciona el autor al respecto se obtendría del excedente generado en las actividades primarias, donde los países periféricos suelen tener elevada productividad.

Es forzoso acudir al excedente real o potencial de la agricultura y otras fuentes de producción primaria [...] Parte del excedente que se capte tiene que emplearse tanto en la agricultura como en dar impulso a una industrialización ineludible. Lo mismo podría decirse con referencia a los recursos naturales no renovables, donde una magnitud desproporcionada del excedente suele desplazarse a los centros. (Prebisch, 1981, p. 309)

Otros mecanismos de captación de recursos con efectos dinámicos que considera Prebisch son el cobro de impuestos al consumo suntuoso, y sobre las actividades que dañan la biosfera.

Ahora bien, el autor reconoce las dificultades que conlleva su transformación. Una de las principales por superar se encuentra en el hecho de que el fomento a las empresas más dinámicas traería consigo una mayor concentración de la economía. En este sentido, Prebisch propone que la fuerza de trabajo vaya apropiándose progresivamente de los excedentes generados por las empresas, a través de la participación en las ganancias generadas por estas.

No hay otra forma de contrarrestar este fenómeno [por la concentración] que la difusión social del capital o la acumulación por el Estado [...] La difusión del capital podrá cumplirse 
dando una participación creciente a la fuerza de trabajo en la nueva acumulación en las empresas gracias al excedente. (Prebisch, 1981, p. 295)

A su vez, para el caso de las empresas medianas y grandes, también recomienda que representantes de los trabajadores participen en las instancias de gestión a través de la conformación de consejos profesionales. El objetivo de estas políticas redistributivas sería la eliminación progresiva de las disparidades sociales de carácter estructural, mientras que continuarían las disparidades funcionales, a fin de mantener el sistema de incentivos.

Si bien Prebisch mismo reconoce que sus propuestas no serían de fácil implementación, y de hecho las somete constantemente a debate, es interesante remarcar que en sus últimos años conservó una virtud que lo distinguió toda su vida: no quedarse solamente en el plano de la crítica y utilizar esta como diagnóstico para pasar pronto a las posibles soluciones.

\section{COMENTARIOS FINALES}

Para algunos, la mejor etapa de Raúl Prebisch es la de la década de 1930, en su calidad de funcionario y hacedor de instituciones, aunque haya colaborado con gobiernos conservadores y fraudulentos. Para la mayoría, realizó sus principales aportes desde la Cepal y la Unctad, donde se proyectó internacionalmente. En este trabajo hemos buscado recorrer su vida profesional y su obra en forma paralela, entendiendo que es la mejor opción para aprovechar su vasto legado intelectual.

Un objetivo particular que nos propusimos fue resaltar la importancia de sus últimas obras. Allí el autor completará su pensamiento sobre el desarrollo latinoamericano, enfatizando la necesidad de elaborar una teoría propia que sirva como guía indispensable para las transformaciones necesarias y que contemple las complejidades de los países periféricos en su integridad, sin eludir las cuestiones sociales y políticas:

Los economistas se obstinan generalmente en eludir los problemas políticos porque escapan al ámbito de la teoría económica. Y la misma asepsia doctrinaria les lleva a prescindir de otros elementos esenciales para comprender la dinámica del desarrollo. Empero, los fenómenos del desarrollo no pueden explicarse solamente con una teoría económica; hay que llegar a una teoría global que integre todos los elementos del sistema mundial del capitalismo [...]. No se trata de prescindir de las teorías de los centros sino en reconocer la especificidad del capitalismo periférico. En otros términos, debe construirse una teoría que abarque al esquema centro-periferia en toda su complejidad. (Prebisch, 1981, pp. 86-87)

Destacamos, al igual que Sunkel et al. (2013), la vigencia del pensamiento de Prebisch para afrontar los problemas actuales de América Latina. El fracaso del modelo neoliberal a fines del siglo XX dio lugar a distintas experiencias políticas y colocó la cuestión del desarrollo de nuevo sobre el tapete, con la desigualdad social en un lugar central. Sin embargo, a más de una década, los problemas en la región han vuelto a aparecer: en algunos casos, por la persistencia de presiones inflacionarias; en otros, por la dependencia de las exportaciones de productos primarios, extremadamente vulnerables a los vaivenes de la economía global, y muchas veces dañinos de la biosfera (Bárcena et al., 2015). Un reciente informe de Cepal (2015) advierte sobre la posibilidad latente de una reversión en el ciclo: 
La región puede padecer problemas de restricción externa, limitados niveles de inversión y las consecuencias de haber mantenido una misma matriz productiva orientada a bienes primarios - la llamada reprimarización-y de no haber aprovechado completamente los beneficios del auge para impulsar el desarrollo de sectores con mayor contenido de conocimiento. Asimismo, es legítimo plantearse cuán sostenible es mantener hacia la baja los niveles de pobreza y desigualdad sin una senda de crecimiento económico estable y dinámico en el largo plazo.

Estas cuestiones ponen de manifiesto la persistencia en América Latina de las dificultades estructurales descriptas por Prebisch y la necesidad de transformaciones más profundas, que de ninguna manera podrían realizarse sin una sólida teoría como guía. En este sentido, celebramos el nuevo impulso que ha cobrado el pensamiento cepalino, incorporando como una dimensión dinámica del desarrollo las cuestiones distributivas (Cepal, 2012, 2015). Entendemos que la teoría de la transformación de Prebisch tiene grandes aportes que hacer en esta nueva etapa del pensamiento económico latinoamericano, sobre todo a través de su interpretación del rol del excedente económico y sus efectos en la acumulación, cuestión que todavía no ha sido del todo explorada. Esperamos que el presente trabajo sirva como un incentivo para ello.

\section{REFERENCIAS}

Altamirano, C. (2001). Bajo el signo de las masas (1943-1973). Buenos Aires: Planeta.

Bárcena, A., Prado, A. \& Abeles, M. (2015). Introducción, En: A. Bárcena, A. Prado \& M. Abeles eds, Estructura productiva y política macroeconómica: enfoques heterodoxos desde América Latina, Libros de la Cepal, No 138 (LC/G.2653-P), pp. 16-27, Santiago.

Caldentey, E. P. \& Vernengo, M. (2013). Reading Keynes in Buenos Aires: Prebisch and the dynamics of capitalism. Working Paper Series, Department of Economics, University of Utah 2013-08.

Caldentey, E. P. \& Vernengo, M. (2012). Banca central y política monetaria en el centro y en la periferia: Prebisch como banquero central y "doctor monetario", Cepal: http://prebisch.cepal.org/es/sigloXXI/banca-central-politica-monetaria

Cepal (1954). La cooperación internacional en la política de desarrollo latinoamericano, Naciones Unidas, Nueva York.

Cepal (2012). Cambio estructural para la igualdad: una visión integrada del desarrollo. (LC/G.2524 (SES.34/3)), Santiago de Chile.

Cepal (2015). Neoestructuralismo y corrientes heterodoxas en América Latina y el Caribe a inicios del siglo XXI.

Di Filippo, A. (1984). Uso social del excedente, acumulación, distribución y empleo. Revista de la Cepal.

Dosman, E. J. (2010). La vida y la época de Raúl Prebisch 1901-1986. Madrid: Ed. Marcial Pons.

Furtado, C. (1978). Prefacio a una nueva economía política. Buenos Aires: Siglo XXI. 
Garegnani, P. (1984). Value and distribution in the classical economists and Marx. Oxford Economic Papers, 36 (2), 291-325.

González, N. \& Pollok, D. (1991). Del ortodoxo al conservador ilustrado. Raúl Prebisch en la Argentina, 1923-1943. Desarrollo Económico, 120, 474-477.

Justo, J. B. (1921). Estudio sobre la moneda. Buenos Aires: Librería Argentina.

Lewis, W. A. (1954). Economic development with unlimited supplies of labour. The Manchester School, 22 (2), 139-191.

Lorenzutti, J. (1996). Dinero, política y bancos. Historia del Banco Central de la República Argentina, 1935-1995. Buenos Aires: Dunken.

Mallorquin, C. (2015). Lord Keynes después de su muerte, según Raúl Prebisch. Estudios Críticos del Desarrollo, 9, segundo semestre, 173-228.

Mallorquin, C. (2006). Textos para el estudio del pensamiento de Raúl Prebisch. Cinta de Moebio. Revista de Epistemología de Cs. Sociales, 25.

Marini, R. M. (1994). La crisis del desarrollismo. En R. M. Marini \& M. Millán (coord), La teoría social latinoamericana: subdesarrollo y dependencia, 2. México: Ediciones El Caballito, pp. 135154.

Nurkse, R. (1953). Problems of capital formation in underdeveloped countries. Nueva York: Columbia UP.

Piñeiro Iníguez, C. (2003). Herejías periféricas. Raúl Prebisch: vigencia de su pensamiento. Buenos Aires: GEL.

Pollock, D., Kerner, D. \& Love, J. (2013). Entrevista inédita a Prebisch: logros y deficiencias de la Cepal. Revista Tendencias, 6 (1-2).

Prebisch, R. (1948). Apuntes de Economía Política (Dinámica Económica), Facultad de Cs. Económicas.

Prebisch, R. (1949). El desarrollo económico de la América Latina y algunos de sus principales problemas. El Trimestre Económico, 347-431.

Prebisch, R. (1973). Problemas teóricos y prácticos del crecimiento económico. Santiago de Chile: Cepal.

Prebisch, R. (1980a). Hacia una teoría de la transformación. Revista de la Cepal, 10, Santiago de Chile.

Prebisch, R. (1980b). Biosfera y desarrollo. Revista de la Cepal, 12, Santiago de Chile.

Prebisch, R. (1981). Capitalismo periférico: crisis y transformación. México: Fondo de Cultura Económica.

Prebisch, R. (1983). Cinco etapas de mi pensamiento sobre el desarrollo. El Trimestre Económico, 198 (2), 1077-1096.

Prebisch, R. (1991a). Obras, 1919-1948, tomo I. Buenos Aires: Fundación Raúl Prebisch.

Prebisch, R. (1991b). Obras, 1919-1948, tomo II. Buenos Aires: Fundación Raúl Prebisch. 
Rapoport, M. (2012). Historia económica, política y social de la Argentina (1880-2003). Buenos Aires: Emecé.

Rapoport, M. (2014). Raúl Prebisch: algunas cuestiones sobre sus ideas y trayectoria en Argentina. FLACSO-ISA Joint International Conference.

Rapoport, M. (2014). Bolchevique de salón: Vida de Félix J. Weil, el fundador argentino de la Escuela de Frankfurt. Buenos Aires: Debate.

Rostow, W. W. ([1960] 1990). The stages of economic growth: A non-communist manifesto. Cambridge: Cambridge University Press.

Sunkel, O., Caldentey, E. P. \& Torres, M. (2013). Raúl Prebisch (1901-1986). Un recorrido por las etapas de su pensamiento sobre el desarrollo económico. Cepal. 